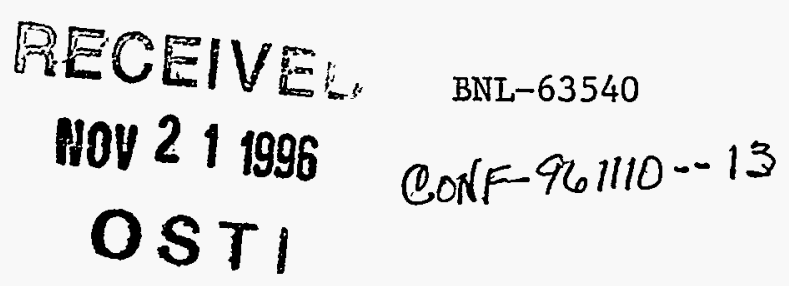

\title{
CORRELATION OF HOLE SIZE IN SUPPORT WINDOWS WITH CALCULATED YIELD STRENGTHS
}

\author{
David J. Schlyer, Mahmoud L. Firouzbakht, Ivonne Garcia and Richard A. Ferrieri \\ Brookhaven National Laboratory, Chemistry Department \\ Upton, NY 11973-5000
}

\begin{abstract}
The operating parameters of thin metal foils supported by thick aluminum grids in use with low energy, high beam current accelerator targets and a comparison between the calculated yield strength and the experimentally determined yield strength for a series of materials and support grid hole size has been investigated. The correlation between theory and experiment is excellent for foils made of aluminum, titanium and Havar. The experimental tensile stress is modeled well by the theoretical equations describing stress on thin circular membranes stretched to the elastic limit.
\end{abstract}

\section{INTRODUCTION}

The use of low energy accelerators in the production of PET radiotracers, although not in common useage, holds promises as a way for hospitals to be able to afford a means to produce the shorter lived PET isotopes on the premises. The main disadvantage of the low energy accelerators is that they must be run at higher beam currents in order to produce sufficient radioisotope to synthesize a reasonable dose of radiotracer. The targetry for these accelerators thus must have some novel features in order to be useful.

In order to use gas targets (e.g nitrogen gas) for the production of the PET isotopes. the foils must be very thin so that the energy of the incident beam is not reduced significantly and at the same time be able to withstand a high heat load generated by the high beam currents necessary at these low energies to produce sufficient radioisotope. Several methods have been used to accomplish this including high aspect ratio windows (1), cooling support bars (2) and beam wobbling at high frequency ( 3 SKAGGS). One method of strengthening the foils is to use a thick support matrix with circular holes leaving enough material between the holes to carry away the heat load by conduction. This matrix can be designed so that more than $50 \%$ of the beam is transmitted through the holes in the foil while the holes are small enough to allow high pressures of gas (>2 atm.) to be used in the target. The theoretical expression of the stress on the foil as a function of the radius of the hole has been described by Westem (4) and others $(5,6,7)$. This equation can be used to predict foil failure. In an effort to test these equations under typical target conditions, a test fixture has been set up which allows testing of different foil thicknesses and hole sizes and comparing the actual failure pressure with that predicted from theory.

DISTRIBUTION OF THIS DOCUNENT $B$ U UHLEATED

\section{EXPERIMENTAL}

All the experiments were carried out using the test fixture pictured in Figure 1. The foil was mounted with the support grid onto the target.
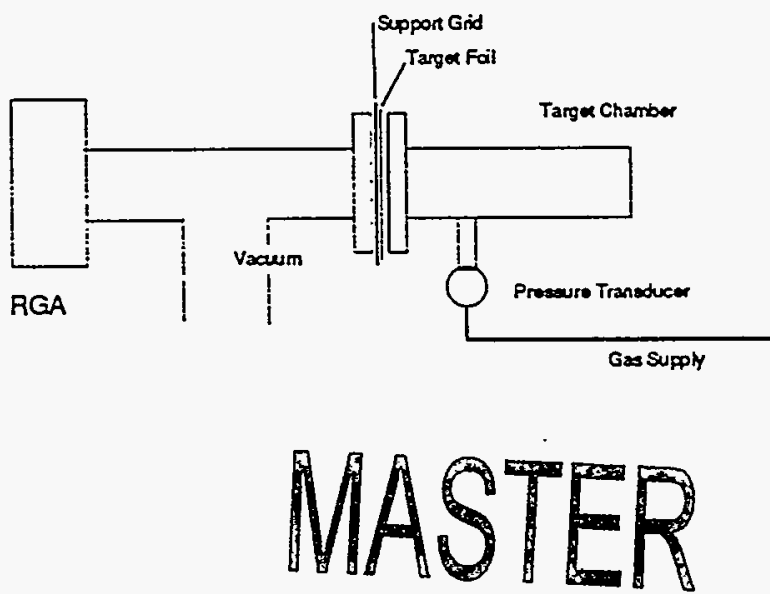

Figure 1. Schematic diagram of yield strength testing apparanus. The foil to be tested is clamped with a viton o-ring and the flanges are connected to the target body with six bolts. Test apparatus is attached to Residual Gas Analyzer.

The target was pressurized with either helium or argon gas. The pressure in the system was gradually increased until a leak appeared in the foil. The pressure at which this occurred was recorded and the procedure repeated. In the early experiments, the initial leak was detected by submerging the target assembly in water. In later experiments, the target assembly was attached to a residual gas analyzer which was set to monitor mass 40 (argon) and record the partial pressure of argon outside the

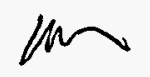




\section{DISCLAMMER}

This report was prepared as an account of work sponsored by an agency of the United States Government. Neither the United States Government nor any agency thereof, nor any of their employees, makes any warranty, express or implied, or assumes any legal liability or responsibility for the accuracy, completeness, or usefulness of any information, apparatus, product, or process disclosed, or represents that its use would not infringe privately owned rights. Reference herein to any specific commercial product, process, or service by trade name, trademark, manufacturer, or otherwise does not necessarily constitute or imply its endorsement, recommendation, or favoring by the United States Government or any agency thereof. The views and opinions of authors expressed herein do not necessarily state or reflect those of the United States Government or any agency thereof. 


\section{DISCLAIMER}

Portions of this document may be illegible in electronic image products. Images are produced from the best available original document. 
target. In general, the residual gas analyzer was used for the aluminum foils and the water method was used for the Havar and titanium since these foils tended to rupture with explosive force while the aluminum foil ruptured by developing a small fissure. This behavior was directly related to ductility of the metal.

The ultimate tensile strength was determined from the formula (5)

$$
S=0.25\left[E p^{2} \frac{a^{2}}{t^{2}}\right]^{1 / 3}
$$

Where:

$$
\begin{aligned}
& S=\text { maximum stress on the membrane (psi) } \\
& E=\text { Young's Modulus (psi) } \\
& p=\text { pressure (psi) } \\
& a=\text { radius of the foil (inches) } \\
& t=\text { thickness of the foil (inches) }
\end{aligned}
$$

The stress calculated from this equation should be equal to the ultimate tensile strength of the membrane. The values for the Young's Modulus and the ultimate tensile strength were taken from the literature $(8,9)$.

In a typical experiment, a foil was cut to the diameter of the front flange. Six holes were punched in the foil to accommodate the screws which attached the front flange to the test apparatus. After assembly, the apparatus was mounted in a large Cajon fitting which attached to the vacuum rack. This formed a vacuum seal and the vacuum chamber containing the front of the test apparatus was evacuated to a base vacuum of $1 \times 10^{-5}$ torr. The residual gas analyzer (Ametek Model M1-200) was tumed on and the mass monitor set to record mass 28 (nitrogen) and mass 40 (argon). As soon as the signal from the residual gas analyzer monitoring the front face of the test apparatus had stabilized, the pressure inside the apparatus was gradually increased by increasing the pressure on a regulator attached to a tank of argon. The pressure inside the apparatus was monitored using a pressure transducer (Omega Model PX181$500 \mathrm{G5V}$ ) attached to the inlet line with a $1 / 4$ " O.D. piece of high pressure plastic tubing. When the trace of the mass 40 peak increased sharply, the pressure was recorded and the gas supply to the apparatus shut off.

\section{RESULTS}

Results at room temperature are plotted for aluminum in Figure 2 along with the theoretical yield strength predicted from the equations. There are no data for the thinnest foil $(.00043$ $\mathrm{cm}$ ) since it was nearly impossible to place this foil on the test assembly without damage. If the foil was creased or damaged in any way, the pressure at which the foil failed was dramatically decreased. There is good agreement between that predicted from theory and the actual foil failure pressure. Each point on the plot represents an average of several points. Without the support grid, the thickest foil $(.00168 \mathrm{~cm})$ ruptured at $14.7 \mathrm{psi}(100 \mathrm{kPa})$ while with a support grid with $1 \mathrm{~mm}$ holes the same foil withstood pressures of more than $310 \mathrm{psi}(2100 \mathrm{kPa})$. The

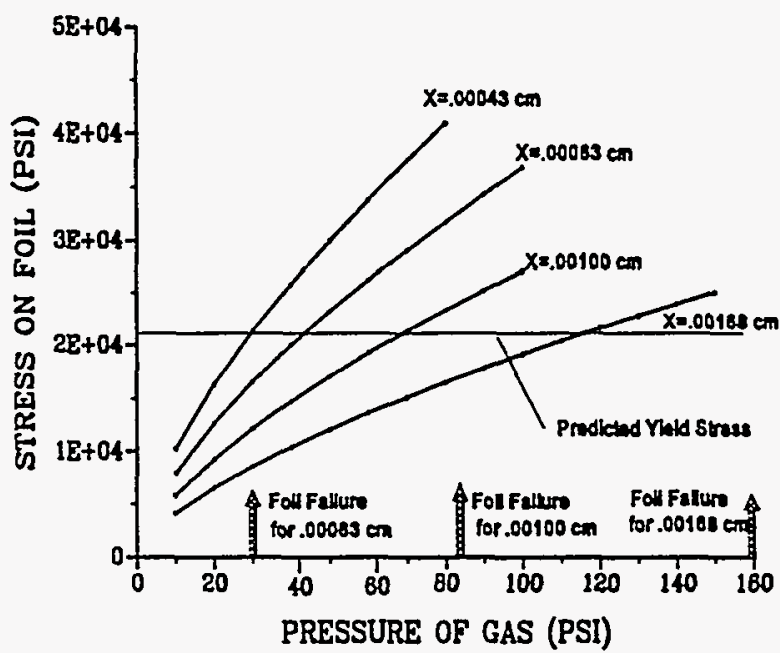

Figure 2 . Plot of predicted stress on foils as a function of gas pressure for four different thicknesses of foils. The predicted yield stress for aluminum at this temperature is shown as a solid line across the plot. The experimental foil failure pressures are shown as arrows on the pressure axis. Each point represents an average of several foil tests.

resuits for aluminum, titanium and Havar are given in Table 1. The values for tensile stress calculated from the formula given in the experimental section and the experimentally determined burst pressures are listed in Table 1 under Experimental YS. The literature values for the ultimate tensile strength are listed under Theoretical YS. There is reasonably good agreement between the experimentally determined numbers and the literature values. 
Table 1 Comparison between Experimental and Calculated Yield Strengths

$\begin{array}{llccr}\text { Eoil } & \text { GridSize } & \text { BurstPressure } & \text { Experimental YS } & \text { Theoretical YS } \\ \text { Aluminum } & & 9 & 23,100 & 20-30,000 \\ 0.001 \mathrm{~cm} & \text { none } & 108 & 34,500 & \\ & 3 \mathrm{~mm} & 164 & 34,800 & \\ & 2 \mathrm{~mm} & 273 & 30,800 & \\ & 1 \mathrm{~mm} & & & \\ 0.0017 \mathrm{~cm} & \text { none } & 14.7 & 22,900 & \\ & 3 \mathrm{~mm} & 162 & 32,000 & \\ & 2 \mathrm{~mm} & 240 & 31,700 & \\ & 1 \mathrm{~mm} & 390 & 27,600 & \\ \text { Titanium } & & & & \\ 0.00127 \mathrm{~cm} & \text { none } & 75 & 93,000 \\ & 4 \mathrm{~mm} & >250 & >71,000 & \\ \text { Havar } & & & & 140,000 \\ 0.00068 \mathrm{~cm} & \text { none } & 55 & 146,000 & \\ & 4 \mathrm{~mm} & 330 & 171,700 & \end{array}$

\section{SUMMARY}

In summary, it has been shown that the pressure at which these thin foils rupture is greatly increased by using a support grid and that the theoretical prediction of yield stress is reasonably accurate for undamaged thin foils.

\section{ACKNOWLEDGMENTS}

This work was carried out at Brookhaven National Laboratory under contract DE-AC02-76CH00016 with the U.S. Department of Energy, supported by its Office of Health and Environmental Research and National Institutes of Health (NS 15380).

\section{REFERENCES}

I.Schulze, M.E., Dabiri, A.E., Holslin, D., and Ghiaasiaan, S.M., Thin Window for an $8 \mathrm{MeV}$ Helium-3 PET RFQ Accelerator Target. Proceedings of the VIh International Workshop on Targetry and Target Chemistry. Villigen Switzeriand, Sept 9-12, 1991.

2. Krohn, K.A., Link, J.M., Weitkamp, W.G., Hagan, W.K., and Young, P., 3 He RFQ for PET Isotope Production: A UW/SAIC Progress Report. Proceedings of the Vit International Workshop on Targetry and Target Chemistry, Upton and Manhasset, New York, Sept 19-23, 1993.

3. Hughey, B.J., Shefer, R.E. Klinkowstein. R.E and Welch, M.J.. Design Considerations for Foil Windows for PET Radioisotope Targets. Procecdings of the VIh International Workshop on Targetry and Target Chemistry. Villigen Switzerland, Sept 9-12, 1991.

4. Skaggs, LS, Kuchnir, F.T., and Waterman. F.M. Experience with thin Havar foils for Cyclotron Target Windows, in Preparation of Nuclear Targets fro Parricle Accelerators J.Jakovsky ed. Plenum pp 249-268. 1981 